\title{
Research Progress of Ceramic Metallization Technology
}

\author{
Yang XIANG ${ }^{1 *}$, Xuechong XIONG ${ }^{2 \star}$, Jin WEN ${ }^{2}$, Guangyao ZHAO $^{3}$, Zhihang PENG ${ }^{1}$, Feng CAO ${ }^{1}$
}

1 Science and Technology on Advanced Ceramic Fibers and Composites Laboratory, College of Aerospace Science and Engineering, National University of Defense Technology, Changsha Hunan, 410073, P. R China

2 Hunan Provincial Key Laboratory of Fine Ceramics and Powder Materials, School of Materials and Environmental Engineering, Hunan University of Humanities, Science and Technology, Loudi Hunan 417000

3 China Construction Machinery Test Center, Changsha Hunan, 410073, P. R China

*Corresponding Author: E-mail: 13873149543@163.com (Xiang Yang)

*Co Author: 591906841@qq.com (Xiong Xue-chong)

\begin{abstract}
:
Due to the wide application of ceramics in electronic device packaging, the performance of ceramic metallization layer directly determines the performance of the whole package device. This paper introduces the main preparation methods of ceramic metallization, discusses the influence of Mo powder size, metallization formula, sintering temperature and other factors on the performance of ceramic metallization layer prepared by activated Mo-Mn method, and introduces several kinds of methods that can be tested to test the performance of ceramic metallized sealing samples. A new research direction of Ceramic Metallization Technology in the advanced field is put forward.

Keywords: ceramic-metal sealing; metallization of ceramics; preparation method
\end{abstract}

\section{Introduction}

With the deepening of the information age, the rapid development of communication, microelectronics and other industries, high-frequency, high-power electronic devices gradually occupy the mainstream of the market. Ceramic materials are widely used in the packaging of electronic devices because of their extremely stable thermal, electrical and mechanical properties.

However, with the gradual improvement of market requirements, the improvement of ceramic packaging technology is becoming more and more important. The key of ceramic packaging technology lies in the connection between ceramics and metals. Due to the difference of properties between the two materials, there is no good infiltration between ceramics and metals. Therefore, the solution is to deposit or sinter a thin metallayer on the surface of ceramics, which is also called ceramic metallization. At the same time, the performance of ceramic metallization layer directly determines the performance of the whole package device. Ceramic metallization technology was first applied in Germany in 1935. In 1958, China officially studied ceramic metallization, and now has a large-scale industrial chain in Beijing, Shanghai, Hunan, Guangdong and other provinces and cities ${ }^{[1]}$.
Since the development of Ceramic Metallization Technology, the main ceramic materials used in practical production and development and application are: $\mathrm{Al}_{2} \mathrm{O}_{3}$, $\mathrm{SiC}, \mathrm{AlN}, \mathrm{BeO}, \mathrm{BN}$, etc., of which $\mathrm{SiC}$ ceramic has high thermal conductivity, but its high dielectric constant and low insulation voltage limit its use in high frequency field; AlN ceramic has excellent electrical and thermal properties, and the material is hard, which can be used in harsh environment However, due to its complex preparation process and high cost, it greatly limits the large-scale development and application of AlN Ceramics. The characteristics of $\mathrm{BeO}$ ceramics are high thermal conductivity, its thermal conductivity can be very close to that of metal materials, and the dielectric constant of $\mathrm{BeO}$ is low, the dielectric loss is small, and the process adaptability is strong. However, due to the toxicity of $\mathrm{BeO}$, the preparation process will cause certain impact on the environment The BN Ceramics have high thermal conductivity, the thermal conductivity almost does not change with the temperature, the dielectric constant and the insulation performance are also suitable, but the raw material CBN is expensive, and it is usually not used in large-scale civil production. $\mathrm{Al}_{2} \mathrm{O}_{3}$ ceramics is the most mature ceramic materials, its advantage is the price Low cost, excellent thermal shock resistance and electrical insulation performance, and the preparation technology 
is very mature, so it plays a leading role in the electronic ceramic industry.

In recent years, the development of ceramic metallization technology has been the concern of scholars at home and abroad. With the coming of $5 \mathrm{~g}$ era, the research on Ceramic Metallization Technology will also usher in another round of peak. In this paper, ceramic metallization as the main research content, combined with the actual production process, the preparation method of ceramic metallization, the influence factors and other aspects on the performance of ceramic metallization layer are introduced.

\section{Preparation method of ceramic metallization}

The commonly used methods of ceramic metallization are Mo-Mn, activated Mo-Mn, direct bonded copper(DBC), active metal brazing(AMB) and magnetron sputtering.

\subsection{Mo-Mn method}

The metallized layer is obtained by adding a small amount of $\mathrm{MnO}$ powder and coating it on the surface of ceramic body with binder and sintering at high temperature. Cao Changwei et al. ${ }^{[2]}$ used the Mo Mn metallization method of $\mathrm{Al}_{2} \mathrm{O}_{3}$ ceramics for reference to metallize the surface of AlN Ceramics after preoxidation. The ceramic layer, metallized layer and nickel layer are close, and the thermal diffusivity of AlN Ceramics is 3.8\% higher than that of AlN Ceramics without preoxidation. The traditional Mo Mn method is suitable for alumina ceramics with high glass content and low alumina content.

\subsection{Direct Bonded Copper method (DBC)}

The technology of direct copper-clad method originates from oxide (such as $\mathrm{Al}_{2} \mathrm{O}_{3}$ ) ceramics. Its principle is that when the temperature is about $1066{ }^{\circ} \mathrm{C}$ (specifically lower than the melting point of copper $\left.10-17{ }^{\circ} \mathrm{C}\right)$, copperoxygen will form a certain amount of eutectic liquid phase containing copper and oxygen, while the existence of eutectic liquid phase will wet the contact copper and ceramic surface, and react with $\mathrm{Al}_{2} \mathrm{O}_{3}$ at the same time, generate composite oxide as solder, making copper It can be closely connected with ceramics ${ }^{[3]}$.

Zhai Tianlei et al. ${ }^{[4]}$ metallized AlN Ceramics by hot pressing and direct copper coating respectively. When the intermediate phase of $\mathrm{Al}_{2} \mathrm{O}_{3}$ and $\mathrm{Cu}_{2} \mathrm{O}$ exists in direct copper coating, the combination of $\mathrm{Cu}$ and AlN Ceramics is closer, which is about 4 times of that of hot pressing. The advantages of the direct copper-clad method lie in the excellent thermal conductivity of the ceramic substrate, the high bonding strength between the metal and the ceramic, and the strong processability ${ }^{[3]}$.

\subsection{Active Metal Brazing method (AMB)}

AMB appears later than Mo Mn method, but because of its advantages such as simple process, high sealing strength and good structure repeatability, it has been one of the main methods of ceramic metal connection.

Active metal is selected as brazing filler metal in active alloy method, and active metal and ceramic are used to react, so that the two can be connected. At present, the active metals used are mainly Ti, on this basis, $\mathrm{Ni}$ based, $\mathrm{Au}$ based, $\mathrm{Cu}$ based active brazing filler metals are developed ${ }^{[5]}$. Xiong Liyuan ${ }^{[6]}$ has successfully realized the connection between AlN Ceramics and oxygen-free copper based on the study of the influence of binder composition in $\mathrm{Ag} \mathrm{Cu}$ $\mathrm{Ti}$ active solder paste on the performance of brazing layer, and the shear strength has reached $75.18 \mathrm{MPa}$, which is slightly better than the product obtained by using imported brazing paste.

\subsection{Magnetron sputtering method}

Magnetron sputtering is a physical vapor deposition method. The main principle of magnetron sputtering is that electrons impact the target under the action of electric field, and the atoms or molecules on the target are deposited on the surface of the substrate. It is characterized by high film-forming rate, low substrate temperature and good adhesion, which can realize large-area coating. Xincl et al. ${ }^{[7]}$ have deposited $\mathrm{Ti} / \mathrm{Mo}$ bilayer film on the surface of $\mathrm{Al}_{2} \mathrm{O}_{3}$ ceramics by magnetron sputtering. After hightemperature sintering, the welding strength of the joint with $\mathrm{Fe} \mathrm{Ni} \mathrm{Co} \mathrm{is} \mathrm{further} \mathrm{improved.} \mathrm{The} \mathrm{welding} \mathrm{strength} \mathrm{is}$ $69.9 \mathrm{MPa}$, which is much better than the metallized samples at $900{ }^{\circ} \mathrm{C}$ and $1050{ }^{\circ} \mathrm{C}$ without obvious TiO.

\subsection{Activated Mo-Mn method}

Activated Mo Mn method was first improved by American L.H. LaForge on the basis of traditional Mo Mn method in $1956^{[1]}$. In order to reduce the sintering temperature and improve the wettability of the glass phase, the appropriate activator was added into the metallized raw material. For the migration process of glass phase in the activated Mo Mn method, Professor Gao Longqiao put forward different opinions. From the unilateral migration of glass phase in the initial ceramics, he thought that in the activated Mo Mn method, the glass phase in the activator and the glass phase in the ceramics migrate with each other, and when the components of the two glass phases reach the same, the sealing effect of the metallized layer is the best ${ }^{[8]}$. Xun Yanhong et al. ${ }^{[9]}$ studied the effect of paste of Mo Mn Ti Si Al System on the metallization of alumina ceramics. For $95 \% \mathrm{Al}_{2} \mathrm{O}_{3}$ ceramics using the paste, the welding strength can reach $150 \mathrm{MPa}$.

Activated Mo Mn process is the most mature and widely used ceramic metallization technology.

\section{Analysis of factors affecting the properties of ceramic metallized layer}

With the continuous development of materials, ceramic metallization technology will keep pace with the continuous progress. Although ceramic metallization technology has been diversified in production and development, there are still many problems for us to further study for these existing technologies. Next, the most widely used and relatively mature activated Mo Mn method will be taken as the research object, focusing on several factors affecting the properties of ceramic metallized layer prepared by activated Mo Mn method. 


\subsection{Particle size of powder}

The effect of powder size on metallization layer is mainly concentrated on Mo powder size. The size of Mo powder particle size will greatly affect the sealing strength of the product. Compared with $3 \mu \mathrm{m}$ Mo powder, the sealing strength of $1 \mu \mathrm{m}$ Mo powder can be increased by more than one time, but the smaller the Mo particle size is, the better. In the production process, too fine Mo powder will produce agglomeration, increase viscosity, not easy to form, and the coating is easy to $\operatorname{crack}^{[10]}$. Cui Ying et al. [11] used dry grinding and wet grinding processes to treat Mo powder. The two processes can greatly reduce the particle size of Mo powder. The median particle size of wet grinding is $\mathrm{D}_{50}=1.78 \mu \mathrm{m}$. the sealing strength of $95 \% \mathrm{Al}_{2} \mathrm{O}_{3}$ ceramics metallized with this Mo powder has been greatly improved, reaching over $350 \mathrm{MPa}$. Li Jingyun et al. ${ }^{[12]}$ found that when fine Mo powder was used to prepare metallized layer, the second metallization process (i.e. nickel plating process) would produce nickel layer blistering, which may be due to the fact that the stress of fine Mo powder could not be effectively released during the sintering process, thus leading to nickel layer blistering. It is suggested that nickel coating and new electroplating process can effectively improve the foaming of nickel layer.

\subsection{Metallization formula}

The introduction of activator is the key of the whole activated Mo Mn method. Different activators have different effects on metallization. Among them, the "three elements" of activator proposed by Professor Gao Longqiao is generally accepted by domestic scholars. The "three elements" of activator refers to the introduction of three basic oxides $\mathrm{MnO}, \mathrm{Al}_{2} \mathrm{O}_{3}$ and $\mathrm{SiO}_{2}$ in the design of metallization formula. The function of different oxides in sintering is also different. $\mathrm{MnO}$ is used to reduce the viscosity of glass phase at high temperature, so as to promote the migration of glass phase; $\mathrm{Al}_{2} \mathrm{O}_{3}$ is used to improve the sealing strength and expand the metallization temperature range; $\mathrm{SiO}_{2}$ can improve the wettability of the framework formed by Mo powder micro oxidation to glass phase, and improve the anti crystallization ability of glass phase ${ }^{[13]}$. In addition, the introduction of other activators can also improve the performance of metallized layer. Yang Xirui ${ }^{[14]}$ respectively used $\mathrm{Bao}$ and $\mathrm{ZrO}_{2}$ as activators to explore the influence of different activators on the metallized layer of alumina ceramics. The results showed that the tensile strength of the metallized layer could reach $138 \mathrm{MPa}$ when the content of Bao was $1.5 \mathrm{wt} \%$, and $121 \mathrm{MPa}$ when the content of $\mathrm{ZrO}_{2}$ was $0.2 \mathrm{wt} \%$. The activation mechanism of the two activators was not the same. Huang Yigong et al. ${ }^{[15]}$ Based on the ceramic metallization of calcium aluminum silicon high alumina ceramics, explored the role of different components in the activator. The research shows that when the mass ratio of $\mathrm{SiO}_{2}$ to $\mathrm{Mn}$ is between 0.54-0.60, glass can be formed, $\mathrm{Al}_{2} \mathrm{O}_{3}$ will expand the scope of glass formation, and $\mathrm{CaO}$ can reduce the crystal phase in the activator melt.

\subsection{Sintering temperature}

Ceramic metallization can be divided into several different processes according to different sintering temperatures: low temperature below $1300{ }^{\circ} \mathrm{C}$, medium temperature from $1300{ }^{\circ} \mathrm{C}$ to $1450{ }^{\circ} \mathrm{C}$, high temperature from $1450{ }^{\circ} \mathrm{C}$ to 1600 ${ }^{\circ} \mathrm{C}$, and extra high temperature above $1600{ }^{\circ} \mathrm{C}$. Different temperatures have their own fields and characteristics ${ }^{[16]}$. If the sintering temperature is too low, the metallized paste will not form glass phase. If the temperature is too high, the glass phase will overflow to the surface of metallized layer, which will affect the plating and sealing strength. Koto White et al. ${ }^{[17]}$ studied the influence of manganese glass on the sealing strength of the metalized layer, they found that the sintering temperature was also critical to the formation of the glass phase. In the low $\mathrm{MnO}$ glass(mass fraction is less than $32 \%$ ), the average tensile strength varies with temperature rise, in the high $\mathrm{MnO}$ glass phase (mass fraction is higher than $43 \%$ ), the average tensile strength of the highest when the sintering temperature is $1300{ }^{\circ} \mathrm{C}, 1450$ ${ }^{\circ} \mathrm{C}$ in the tensile strength decreased, while the main reason is that $1350{ }^{\circ} \mathrm{C}$ high $\mathrm{MnO}$ glass phase alumina crystal growth affected the tensile strength. Huang Yigong et al. ${ }^{[18]}$ through the research on the influence of wet hydrogen on the quality of metallized layer in BTU horizontal hydrogen furnace, found the cause of the blackening of ceramic glaze layer in the process of ceramic metallization, analyzed the influence of water vapor content in wet hydrogen on the quality of metallized layer, and provided an important idea for improving the strength of metallized layer. Zhong Wei et al. ${ }^{[19]}$ simulated and calculated the instantaneous temperature in the high-temperature hydrogen furnace by establishing the three-dimensional flow and heat transfer mathematical model of alumina ceramic metallization process. The results show that the maximum temperature difference in different positions of the high-temperature hydrogen furnace is $26{ }^{\circ} \mathrm{C}$, and the setting temperature for metallization is generally low, which also provides an important basis for optimizing the hydrogen furnace structure and further improving the temperature uniformity of the hydrogen furnace. Accurately controlling the sintering process is the key to the success of the ceramic metallization layer. Only fully considering the influence of sintering temperature and other factors on the formation of the metallization layer, can the ceramic metallization layer with better performance be prepared.

\subsection{Others}

Microstructure: Microstructure directly affects the bonding strength and air tightness of ceramic metal materials. Through the study of microstructure, it can play a guiding role in improving components and optimizing process. The section layer of weldment with better welding performance should be clear. Only when the interface of each interface layer is clear can it be proved that the interface layers are firmly connected by chemical bonding, without forming a fragile middle layer or being damaged. If the structure of the metallized layer is loose, the Ni layer or the solder layer will enter into the metallized layer, which 
will affect the welding strength, and the air will be released under vacuum due to the poor air tightness ${ }^{[20]}$.For ceramic matrix, the matrix porosity and pore diameter size also influences the glass phase diffusion, manganese content in the aperture size of glass phase manganese content in the capillary force is the main driving force, porosity is directly affecting the manganese content in the matrix of the absorption rate of glass phase, and glass phase content in the matrix affects the manganese content of glass phase diffusion depth, so the metallized layer of organization evolution and mechanics performance change is also affected by the matrix microstructure ${ }^{[21]}$.

Coating method: Coating methods affect the uniformity of metallized paste coating. The existing coating methods mainly include manual coating, screen printing, spray gun spraying, etc. For products with relatively small quantity and inconsistent size and scale, manual coating should be adopted, while for large-scale factory production, screen printing process is generally adopted, with good coating uniformity and basically consistent product thickness. The coating thickness should be $50 \mu \mathrm{m}^{[22]}$.

Organic components: In the coating process of generic paste, in order to ensure that it has certain process performance: viscosity, rheology, thixotropy, plasticity, etc., it is necessary to add appropriate and appropriate amount of binder, diluent, thixotropic agent, plasticizer and other organic compounds. For different coating methods, the composition of organic matter is different. The paste for manual coating is made of nitric acid fiber as binder, amyl acetate as solvent, and the viscosity of the paste is 1.20 1.40Pa.s; the paste for screen printing is made of ethyl cellulose and terpineol (or ethanol, n-butanol) as solvent, and the viscosity of the paste is about $25 \mathrm{~Pa} \cdot \mathrm{s}^{[1]}$.

\section{Performance test method of ceramic metal- lization}

At present, the main testing methods for ceramic metallization are: metallographic microscopy, scanning electron microscopy (SEM) and X-ray fluorescence thickness gauge to observe the microstructure and thickness ${ }^{[23]}$; EDX energy spectrum analysis to detect the regional elements of metallization layer to understand the reaction process in the sintering process; X-ray diffraction to analyze the phase of metallization layer Test the tensile strength of sealing sample with electronic universal testing machine ${ }^{[24]}$; test the fatigue resistance of sealing sample with electro-hydraulic servo fatigue testing machine ${ }^{[25]}$; test the air tightness of sealing sample with helium mass spectrometer leak detector ${ }^{[26]}$.

\section{Summary}

After decades of continuous development, the application field of ceramic metallization technology continues to expand, from semiconductor chips, auto parts, vacuum switches and other life-related fields to military radar, basic communication, new energy development and other important fields, ceramic metallization technology has gradually become the basis of its development. China's ceramic metallized sealing devices have gradually met the basic needs of the country, but we still need to carry out further research in the high-end field. There are still some problems in Ceramic Metallization Technology to be discussed:

(1) High power, high frequency electronic devices are the main direction of future development, so the development of better performance, higher quality sealing devices still need to be focused on;

(2) The optimization of technological process, the reduction of production energy consumption and production cost, and the realization of large-scale production of products are still to be explored;

(3) The formulation of product quality standards needs to be further improved.

The continuous improvement of ceramic metallization technology is the premise of the progress of ceramic metal sealing technology. I believe that with the continuous efforts of the industry, ceramic metal sealing technology will continue to move forward steadily.

Conflict of Interest: To the best of our knowledge, the productions of this paper are original. All authors have read the paper and agree to this statement of originality. Finally, this paper is our original unpublished work and it has not been submitted to any other journal for reviews. The authors have obtained the necessary authority for publication. If accepted, this paper will not be published elsewhere in the same form, in English or in any other language, without the written consent of the Publisher.

Acknowledgments: The authors are grateful to National Science Foundation of China (51602347) and Hunan Natural Science Foundation (2019JJ50282) for financial support. The authors are also grateful to Aid Program for Innovative Group of National University of Defense Technology and Aid Program for Science and Technology Innovative Research Team in Higher Educational Institutions of Hunan Province.

\section{References}

[1] GaoLQ,LiuZ.ProgressofCeramictoMetalSealTechnology in China[J].Shandong Ceramics,2019,42(02):7-12. (In Chinese)

[2] Cao C W, Feng Y B, Qiu T, Liang T. Surface Oxidation and Metallization of AIN Ceramics by Mo-Mn Process[J]. Journal of Synthetic Crystals, 2017,46(03):416-421+432. (In Chinese)

[3] Chen D Q, Lin F, Xiao L R, Qiu T, Cai H P, Jiang X L, Yi D Q. Research and Development of DBC packaging Materials. 2004(06):76-78+82.(In Chinese)

[4] Zhai T L, Lin G A, Yao B, Ding M M, Xie J J, Shi YY, Li D S, Wu, $\mathrm{Z} \mathrm{H}$. Interface Bonding Properties and Microstructure of AIN/Cu Composite Substrate[J]. Journal of the Chinese Ceramic Society, 2017,45(07):1037-1042.(In Chinese) 
[5] Wang Y, Cao J, Zhang L X, Feng J C. Review on active brazing of alumina ceramic and metal[J], Welding \& Joining,2009(02):56-60+71.(In Chinese)

[6] Xiong L Y. Preparation and Characterization of Ag-CuTi Active Paste for Brazing[D], Nanjing University of Aeronautics and Astronautics, 2018.(In Chinese)

[7] Xin C L, Liu W B, Li N, et al. Metallization of Al2O3 ceramic by magnetron sputtering $\mathrm{Ti} / \mathrm{Mo}$ bilayer thin films for robust brazing to Kovar alloy [J]. Ceramics International, 2016,42(8):9599-9604.

[8] Gao L Q, Gao Y Q. Total Process of Glass Phase Migration in Ceramic Metallization[J]. Shandong Ceramics, 2010,33(04):3-5+16. (In Chinese)

[9] Xun Y H, Zhang J X, Chen M L, Gao L Q. Processing of Metallizing Alumina Ceramic with Mo-Mn-Ti-Si-Al System Paint[J]. Vacuum electronics, 2011(01):26-29.(In Chinese)

[10] Gao L Q. Molybdenum Powder and Ceramic Metallizing Technology[J]. Vacuum Electronics, 2012(04):1-5+15.(In Chinese)

[11] Cui Y, Can A F, Chen X H, Huang Y G. The Influence of Mo Powders on Metallizing[J]. Vacuum Electronics,2013(04):88-91.(In Chinese)

[12] Li J Y, Zhao R F. Effects of the Fine Molybdenum Powder on the Quality of 95\% Alumina Ceramics Metallizing and the Analysis of Existing Problems[J]. Vacuum Electronics, 2014(04):67-71.(In Chinese)

[13] Gao L Q. Design Principle of the Ceramic Metallizing Formulae[J]. Vacuum Electronics, 2002(03):21-23.(In Chinese)

[14] Yang X R. Preparation and Properties of Metallization Layer used for Packaging Transistors, Shandong University,2016.(In Chinese)

[15] Huang Y G, CaiA F, Liu Y Q, Liu H Q. Various Components of Activating Agent for Molybdenum Manganese Metallization Play the Role in the Formulation[J]. Vacuum Electronics, 2008(04):42-46+59.(In Chinese)

[16] GAO L Q, Recent Development of Ceramic to Metal Seal and Its Relative Technology[J]. Vacuum Electronics,
2000(05):20-26.(In Chinese)

[17] KOTO WHITE, Daniel P. KRAMER. Microstructure and Seal Strength Relation in the Molybdenum-Manganese Glass Metallization of Alumina Ceramics[J]. Materials Science and Engineering, 1985,75(1-2):207-213.

[18] Huang Y G, Liu X F, Liu H Q, The Influence of Hydrogen Humidity on Product Quality of Ceramic Metallization[J]. Vacuum Electronics, 2010(02):54-58.(In Chinese)

[19] Zhong W, Zou G J. Modeling and Simulation of Temperature Field in Al2O3 Ceramic Metallization[J]. 2016,36(06):718-722.(In Chinese)

[20] Zhang J X. Microstructure of Metallized Alumina Ceramics Applied in Vacuum Electronics Comp onents of Domestic and Oversea[J]. Vacuum Electronics, 2003(04):27-28+39. (In Chinese)

[21] Wang L, Kang W T, Guo P Z, et al. Influence of Ceramic Substrate Porosity and Glass Phase Content on the Microstructure and Mechanical Properties of Metallized Ceramics via an Activated Mo-Mn method [J]. Ceramics International, 2020,46(6):8244-8254.

[22] Wang L, Kang W T, Gao P Z, Kang D H, Zhang $\mathrm{H} \mathrm{H}$. Research Progress of Methods, Mechanisms and Influencing Factors of Ceramic Metallization[J]. Journal of Ceramics, 2019,40(04):411-417.(In Chinese)

[23] Cheng $W \mathrm{Q}$, Chen J H. Analysis and Discussion on Measuring the Thickness of Ceramic Metallization Layer with Different Testing Equipment[J]. Ceramics Science \& Art, 2010,(10):18-20.(In Chinese)

[24] Cheng W Q. Test and Application of Ceramic-Metal Sealing Tensile Strength[J]. Ceramics Science \& Art, 2006(02):4-6.(In Chinese)

[25] Shi M, Zheng J X, Gao L Q, Liu Z. Study on Fatigue Behaviors of Metalized Al2O3 Ceramic Seals[J]. Bulletin of The Chinese Ceramic Society, 2012,31(04):10351038.(In Chinese)

[26] Qi L J, Zheng J P, Lei H Z. Brazing Process and Application Performance of Monocrystal Al2O3 Ceramic/Nb-1Zr Alloy Sealing Parts[J]. Vacuum Electronics, 2016(01):5863. (In Chinese) 